\title{
Many Roles of Transcriptional Factor Brachyury
}

ISSN: 2637-773X

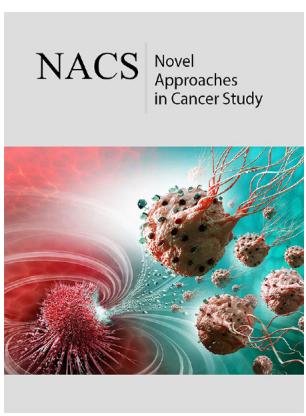

*Corresponding author: Jun Shen, Department of Orthopeadic Surgery, the Affiliated Suzhou Hospital of Nanjing Medical University; Suzhou Municipal Hospital. Suzhou, Jiangsu, 215002, People's Republic of China

Submission: 眮 May 20, 2021

Published: 眥May 25, 2021

Volume 5 - Issue 5

How to cite this article: Ming Chen, Keqin Shi,Jun Shen. Many Roles of Transcriptional Factor Brachyury. Nov Appro in Can Study. 5(5). NACS.000624. 2021. DOI: 10.31031/NACS.2021.05.000624

Copyright@ Jun Shen, This article is distributed under the terms of the Creative Commons Attribution 4.0 International License, which permits unrestricted use and redistribution provided that the original author and source are credited.

\section{Ming Chen ${ }^{1}$, Keqiin Shi ${ }^{1}$ and Jun Shen ${ }^{2 *}$}

${ }^{1}$ Department of Orthopeadic Surgery, the Affiliated Wuxi No.2 People's Hospital of Nanjing Medical University. Wuxi, Jiangsu, 214000, People's Republic of China

${ }^{2}$ Department of Orthopeadic Surgery, the Affiliated Suzhou Hospital of Nanjing Medical University; Suzhou Municipal Hospital. Suzhou, Jiangsu, 215002, People’s Republic of China

\section{Introduction}

Brachyury gene, firstly discovered in 1927, encodes a protein of 435 amino acids, which functions as a transcription factor regulating posterior mesoderm formation and notochord differentiation, and plays many roles in carcinogenesis and other some biological process.

\section{Brachyury in notochord formation and notochord cell-derived cells}

Brachyury is essential to maintain notochord cell fate and function [1]. Chordoma is a rare malignant tumor originated from notochordal cell rests. Chordoma patients with higher Brachyury expression showed significantly shorter progression-free survival. Brachyury was suggested as a prognostic biomarker in chordoma. Further Brachyury was found to promote chordoma cell growth via PI3K/Akt signaling [2]. The origin of intervertebral disc cells is always considered to be associated with notochord cells. Brachyury was found to have the capability of reprogramming degenerative human intervertebral disc cells to a healthy phenotype [3]. Our research has also found that Brachyury can protect the intervertebral disc cells from degeneration.

\section{Brachyury promotes tumor cells invasiveness in various types of cancers}

Brachyury also plays an important role in the development of many epithelium origin tumors. In lung cancer patients, high expression of the Brachyury protein was significantly associated with poor prognosis [4]. Our previous study indicated that Brachyury promotes tumor cells proliferation and inhibits apoptosis in Non-Small Cell Lung Cancer (NSCLC) H460 cells [5].

In breast cancer, nuclear expression of Brachyury is an independent marker that predicts poor prognosis [6]. Brachyury is reported to be overexpressed in triple negative breast cancer and mediates epithelial-mesenchymal transition [7,8]. Brachyury is also associated with chemotherapy resistance in breast cancer [9]. Our previous study indicated that Brachyury could promote breast cancer metastasis to bone. SOX5 knockdown in Brachyury-expressing breast cancer cells resulted in a significant reduction in survival and tumorigenic capabilities in the bone microenvironment [10]. In gastrointestinal stromal tumors, Brachyury can lead to aggressiveness and poor survival [11]. High Brachyury expression is associated with metastasis and poor prognosis in oral squamous cell carcinoma. Brachyury synergistically promotes self-renewal and invasiveness with other transcriptional factor in oral cancer cells, which is expected to develop into specific therapeutic targets [12,13]. Brachyury has been reported to involve in the progression of prostate cancer and contributes to tumor chemotherapy resistance [14]. Brachyury also plays an oncogenic role in testicular germ cell tumors and its nuclear localization is suggested as a novel biomarker of poor prognosis [15].

In conclusion, Brachyury has become an attractive therapeutic target not only in various types of cancers but also in regenerative medicine. The thorough investigation of the upstream and downstream regulatory pathways of Brachyury in different contexts will facilitate the development of related drugs or other therapeutic strategies. 


\section{Acknowledgement}

This work was supported by Scientific research project of Wuxi Health Commission (Grant No. Q202006). No benefits in any form have been or will be received from a commercial party related directly or indirectly to the subject of this manuscript.

\section{References}

1. Zhu J, Kwan KM, Mackem S (2016) Putative oncogene brachyury (T) is essential to specify cell fate but dispensable for notochord progenitor proliferation and EMT. Proc Natl Acad Sci USA 113(14): 3820-3825.

2. Otani R, Mukasa A, Shin M, Omata M, Takayanagi S, et al. (2018) Brachyury gene copy number gain and activation of the $\mathrm{PI}_{3} \mathrm{~K} / \mathrm{Akt}$ pathway: Association with upregulation of oncogenic brachyury expression in skull base chordoma. J Neurosurg 128(5): 1428-1437.

3. Tang S, Richards J, Khan S, Hoyland J, Daniel P, et al. (2019) Nonviral transfection with brachyury reprograms human intervertebral disc cells to a pro-anabolic anti-catabolic/inflammatory phenotype: A proof of concept study. J Orthop Res 7(11): 2389-2400.

4. Lee KH, Kim EY, Yun JS, Yong L, Sung I, et al. (2018) Prognostic significance of expression of epithelial-mesenchymal transition driver brachyury in breast cancer and its association with subtype and characteristics. Oncol Lett 15(1): 1037-1045.

5. Xu J, Chen M, Wu Y, Zhang H, Zhou J, et al. (2020) The role of transcriptional factor brachyury on cell cycle regulation in non-small cell lung cancer. Front Oncol 10: 1078.

6. Lee KH, Kim EY, Park YL, Do SI, Chae SW, et al. (2017) Expression of epithelial-mesenchymal transition driver brachyury and status of tumorinfiltrating $\mathrm{CD} 8+$ and $\mathrm{FOXP}_{3}+$ lymphocytes in predicting treatment responses to neoadjuvant chemotherapy of breast cancer. Tumour Biol 39(6): 1010428317710575.
7. Li K, Ying M, Feng D, Chen Y, Wang J, et al. (2016) SMC1 promotes epithelial-mesenchymal transition in triple-negative breast cancer through upregulating Brachyury. Oncol Rep 35(4): 2405-2412.

8. Hamilton DH, Roselli M, Ferroni P, Costarelli L, Cavaliere F, et al. (2016) Brachyury, a vaccine target, is overexpressed in triple-negative breast cancer. Endocr Relat Cancer 23(10): 783-796.

9. Li K, Ying M, Feng D, Du J, Chen S, et al. (2016) Brachyury promotes tamoxifen resistance in breast cancer by targeting SIRT1. Biomed Pharmacother 84: 28-33.

10. Chen M, Zou S, He C, Zhou J, Li S, et al. (2019) Transactivation of SOX by Brachyury promotes breast cancer bone metastasis. Carcinogenesis 41(5): 551-560.

11. Pinto F, Campanella NC, Abrahão-Machado LF, Scapulatempo C, Oliveira A, et al. (2016) The embryonic brachyury transcription factor is a novel biomarker of GIST aggressiveness and poor survival. Gastric Cancer 19(2): 651-659.

12. Yoshihama R, Yamaguchi K, Imajyo I, Mine M, Hiyake N, et al. (2016) Expression levels of $\mathrm{SOX}_{2}, \mathrm{KLF}_{4}$ and brachyury transcription factors are associated with metastasis and poor prognosis in oral squamous cell carcinoma. Oncol Lett 11(2): 1435-1446.

13. Akimoto N, Nakamura K, Hijioka H, Kume K, Matsumura $\mathrm{Y}$, et al. (2018) Transfection of T-box transcription factor brachyury and SOX synergistically promote self-renewal and invasive phenotype in oral cancer cells. Int J Mol Sci 19(11): 3620.

14. Pinto F, Pértega-Gomes N, Vizcaíno JR, Andrade RP, Cárcano FM, et al. (2016) Brachyury as a potential modulator of androgen receptor activity and a key player in therapy resistance in prostate cancer. Oncotarget $7(20)$ : 28891-28902.

15. Pinto F, Cárcano FM, da Silva E, Vidal D, Scapulatempo C, et al. (2018) Brachyury oncogene is a prognostic factor in high-risk testicular germ cell tumors. Andrology 6(4): 597-604. 